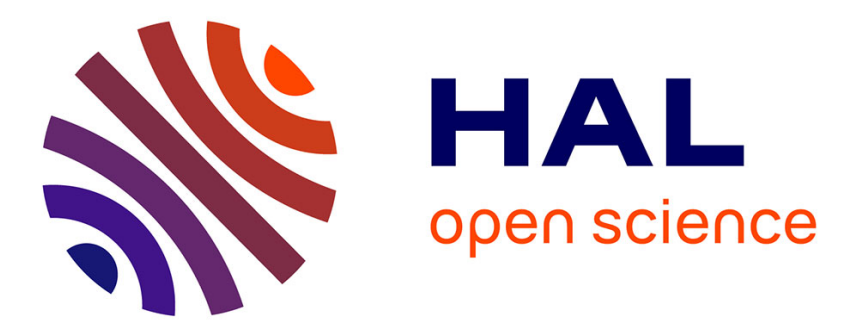

\title{
Un manuel de piété pour les Noirs et les gens de couleur en Argentine (1839), traduction de celui de l'abbé Grégoire pour Haïti (1822)

\author{
Jean-Pierre Tardieu
}

\section{- To cite this version:}

Jean-Pierre Tardieu. Un manuel de piété pour les Noirs et les gens de couleur en Argentine (1839), traduction de celui de l'abbé Grégoire pour Haïti (1822). Outre-Mers Revue d'Histoire, 2017, 396-397, pp.203-225. hal-01629491

\section{HAL Id: hal-01629491 \\ https://hal.univ-reunion.fr/hal-01629491}

Submitted on 31 Oct 2018

HAL is a multi-disciplinary open access archive for the deposit and dissemination of scientific research documents, whether they are published or not. The documents may come from teaching and research institutions in France or abroad, or from public or private research centers.
L'archive ouverte pluridisciplinaire HAL, est destinée au dépôt et à la diffusion de documents scientifiques de niveau recherche, publiés ou non, émanant des établissements d'enseignement et de recherche français ou étrangers, des laboratoires publics ou privés. 


\title{
Un manuel de piété pour les Noirs et les gens de couleur en Argentine (1839), traduction de celui de l'abbé Grégoire pour Haïti (1822).
}

\author{
Jean-Pierre Tardieu*
}

\begin{abstract}
Résumé. Le Manuel de piété à l'usage des hommes de couleur et des Noirs de l'abbé Grégoire, édité en 1822 pour Haïti, a été fidèlement reproduit en espagnol en 1839 pour Buenos Aires, où se trouvait une forte communauté d'origine africaine. Or si l'histoire de l'île caribéenne et celle du Río de la Plata avaient en commun l'esclavage des Noirs, l'évolution du système fut bien différente dans chaque pays. Il n'avait pas encore été aboli en Argentine à l'époque de la publication. Toutefois les éditeurs argentins, dans le contexte agité du gouvernement de Rosas qui s'appuyait sur les masses populaires, avaient probablement pensé à utiliser les propositions de Grégoire au sujet de la régénération de l'homme de couleur et du Noir à partir d'un strict encadrement chrétien.
\end{abstract}

Mots clé : 1839-Buenos Aires- Abbé Grégoire- Régénération chrétienne-Noirs-Haïti-1822

\begin{abstract}
The Piety Handbook for Colored Men and Blacks edited by the Abbé Grégoire for Haiti in 1822 was faithfully translated in Spanish in 1839 for Buenos Aires where was a strong community of African origin. Now if the histories of the Caribbean Island and of Río de la Plata had the black slavery in common, his evolution was very different in each country. In the period of the publication of this handbook, the slavery was not abolished yet in Argentina. Nethertheless the argentinian editors, moved by the unsettled context of the Rosas' government who was based on the popular masses, thought probably to make use of the Gregoire's propositions about the regeneration of the Colored Men and the Blacks from a strict christian management.
\end{abstract}

Keywords : 1839-Buenos Aires-Abbé Grégoire-Christian regeneration-Blacks-Haiti-1822 
Je me suis longtemps intéressé aux catéchismes destinés aux Noirs des Amériques espagnoles coloniales ${ }^{1}$. C'est à ce titre que l'anthropologue argentin Noberto Pablo Cirio m'a fait part de l'existence dans les fonds de la Bibliothèque Nationale de Buenos Aires d'un ouvrage religieux destiné aux Noirs, dont il a eu l'obligeance de me fournir la photocopie ${ }^{2}$. Ce n'est pas seulement un recueil de prières ${ }^{3}$ ou un catéchisme adapté à ses destinataires ${ }^{4}$, mais plutôt un livret proposant une ligne de conduite pour les chrétiens d'origine africaine. Intitulé Manual de piedad para el uso de los hombres de color y de los negros, il est la traduction anonyme publiée à Buenos Aires en 1839 d'un ouvrage de «l'ancien évêque de Blois », sans plus de précision quant à son auteur'. Il s'agit du Manuel de piété à l'usage des hommes de couleur et des Noirs de l'abbé Grégoire. Non pas de l'édition de $1818^{6}$ parue chez les frères Baudouin et Aimé Comte à Paris, mais celle de $1822^{7}$, éditée par les seuls frères Baudouin. Les éditeurs argentins respectèrent scrupuleusement cette édition, fort bien traduite d'ailleurs ${ }^{8}$. Il est curieux de savoir comment ils en sont venus à choisir un manuel destiné à

\footnotetext{
*Jean-Pierre Tardieu, professeur émérite de civilisation hispano-américaine à l'université de La Réunion, travaille sur les Noirs aux Amériques coloniales espagnoles, sujet sur lequel il a publié plusieurs livres.

${ }^{1}$ Jean-Pierre Tardieu, L'Eglise et les Noirs au Pérou (XVI ${ }^{e}-X V I I^{e}$ siècles), Paris : L'Harmattan, 1993.

${ }^{2}$ Références de l'étiquette collée sur la couverture : « $49375 »$, et, porté à la main, l'inscription «997-A Bis ».

${ }^{3}$ Comme les Oraciones traducidas en lengua del Reino de Angola, imprimées à Lima en 1629, dont nous avons pu suivre la composition mais qui ont disparu ; voir J.-P.Tardieu, op. cit.

${ }^{4}$ On citera par exemple le Catecismo Breve para los rudos y ocupados de 1584, premier livre imprimé en Amérique du sud, plus précisément à Lima, qui présente un effort pédagogique notoire (voir : J.-P. Tardieu, op. cit.), ou, pour beaucoup plus tard, à Cuba, l'Explicación de la Doctrina Christiana acomodada a la capacidad de los Negros Bozales, rédigée en 1796 par Nicolás Duque de Estrada, que l'on consultera dans l'édition de Javier Laviña, Barcelone : Sendai Ediciones, 1989.

${ }^{5}$ L'utilisation de manuels français traduits en espagnol pour l'enseignement religieux à Buenos Aires n'était pas rare. On se servait du Catecismo histórico de l'abbé Fleury, imprimé à Paris à partir des années 1830. Voir : Clara Brafman, «Les manuels scolaires de lecture d'origine française en Argentine dans la deuxième moitié du XIX ${ }^{\mathrm{e}}$ siècle », Histoire de l'éducation 69 / 1, 1996, p. 66.

${ }^{6}$ Pour consulter cette édition :

https://books.google.com/books?id=XTgh2TawkaEC\&lpg=PA58\&ots=YCkR_1J8XK\&dq=\%22manuel\%20de\% 20pi\%C3\%A9t\%C3\%A9\%22\%20gr\%C3\%A9goire\%20henri\%20baptiste\&hl=fr\&pg=PP1\#v=onepage\&q=\%22 manuel\%20de\%20pi\%C3\%A9t\%C3\%A9\%22\%20gr\%C3\%A9goire\%20henri\%20baptiste\&f=false

${ }^{7}$ Pour consulter cette édition :

https://books.google.com/books?id=PRVmAAAAcAAJ\&pg=PA62\&lpg=PA62\&dq=\%22manuel+de+pi\%C3\% A9t\%C3\%A9\%22+gr\%C3\%A9goire+henri+baptiste\&source=bl\&ots=QP4tyy7dS9\&sig=xzskip872hHD3sqqUij OyB7Zv4A\&hl=fr\&sa=X\&ved=0ahUKEwjpy6TP_KvMAhUFiRoKHcRSDrgQ6AEIKzAE\#v=onepage\&q=\%2 2manuel\%20de\%20pi\%C3\%A9t\%C3\%A9\%22\%20gr\%C3\%A9goire\%20henri\%20baptiste\&f=false

L'abbé Grégoire y traite plus longuement (88 lignes supplémentaires) :

- du « libertinage », des vertus de la femme et de la mère chrétiennes, de la vanité ;

-des saints hispano-américains ;

-des saints qui ont œuvré particulièrement pour la liberté des esclaves.

Ces deux derniers types de rajouts traduisent la volonté de l'auteur d'insister davantage sur ce que nous appellerions aujourd'hui l'inculturation des hommes de couleur et des Noirs d'Haïti.

${ }^{8}$ Un seul petit contresens est à noter, induit par la ressemblance phonétique de deux termes : «Voilà, mes frères, des réflexions que je vous engage à méditer» (édition de 1822, p. 39), devient: "Ved aquí, mis hermanos, reflexiones que os induzco a imitar $»$ (édition argentine, p.67-68).
} 
l'instruction religieuse des habitants d'Haïti pour en proposer l'application aux Noirs de la capitale de la jeune république argentine, dans un contexte à l'évidence bien différent.

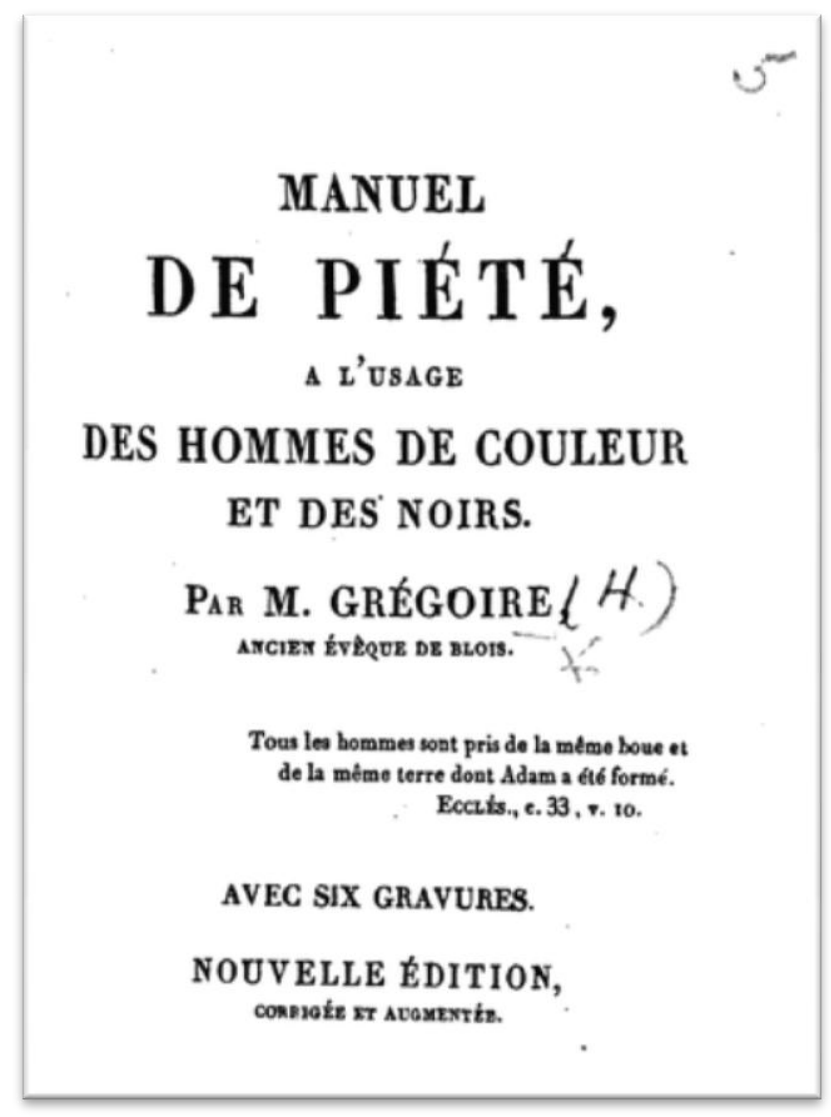

Edition de 1822

\section{1-Présentation de l'ouvrage}

L'ouvrage comporte 59 pages de texte, sans compter les pages préliminaires (licence, index, présentation des éditeurs) et celles des illustrations. Voici une reproduction de la page de titre et une transcription des pages précédant le texte lui-même. 


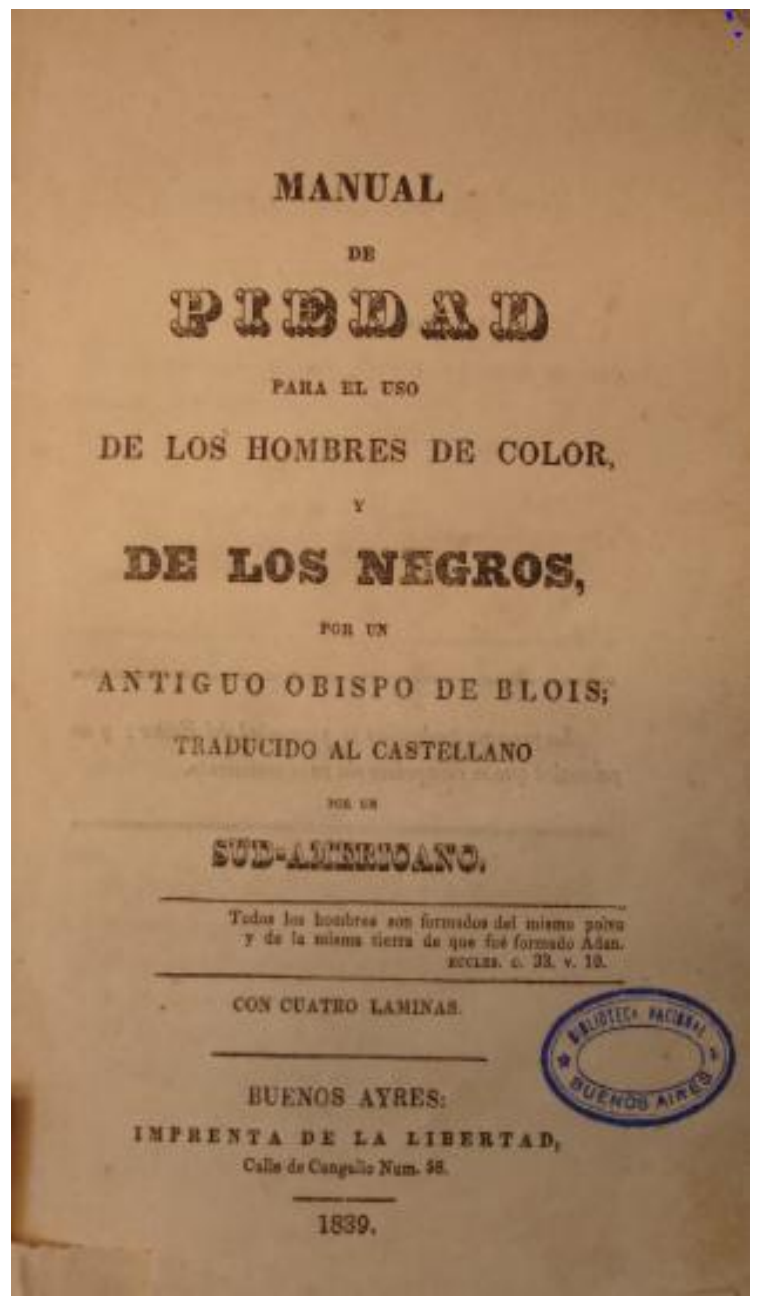

a-D'abord le titre en gros caractères de fantaisie :

MANUEL / DE / PIEDAD / PARA EL USO / DE LOS HOMBRES DE COLOR, / Y / DE LOS NEGROS, /

b-Puis viennent, toujours en majuscules mais en caractères plus petits, les références à l'auteur et au traducteur :

POR UN / ANTIGUO OBISPO DE BLOIS ; / TRADUCIDO AL CASTELLANO / POR UN / SUD-AMERICANO.

c-Le titre est suivi du verset 10, chapitre 33, de l'Ecclésiastique : 
«Todos los hombres son formados del mismo polvo y de la misma tierra de que fue formado Adan ».

d-Quatre planches d'illustration sont annoncées.

e-Puis sont précisées la localisation et l'année de l'édition :

BUENOS AYRES : / IMPRENTA DE LA LIBERTAD, / Calle de Cangallo Num. 58. 1839

f-Felipe Elortondo y Palacio, secrétaire du Dr. Don Mariano Medrano y Cabrera, évêque de Buenos Ayres, délivra au nom de son supérieur la licence d'impression le 6 février 1839.

g-Le prélat accorda diverses indulgences aux lecteurs :

-40 jours pour la lecture réfléchie de chaque chapitre de l'œuvre,

-40 jours pour chaque pensée aux passages des Saintes Ecritures contenus dans l'œuvre,

-40 jours pour la lecture de chaque mot de la Litanie,

-40 jours pour celle de chaque réponse,

-40 jours pour chacune des invocations à la gloire divine (preces),

-40 jours pour chaque prière.

h-La traduction de l'index est la suivante :

Page

Aux hommes de couleur et aux noirs..........................................

Pensées extraites des Saintes Ecritures........................................... 16

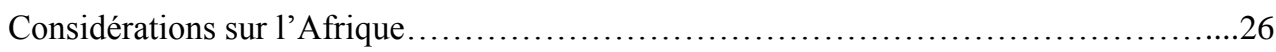

Du culte des Saints en général, et de ceux de l'Afrique en particulier...................34

Litanie des Saints.........................................................42

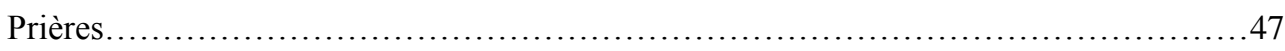

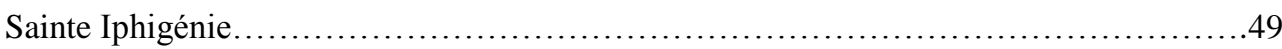

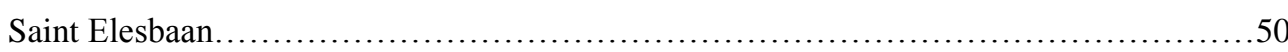

Les deux Bienheureux Antoine de Caltagiro et Antoine de Noto..........................id.

Saint Benoit le Maure............................................................... 
i-Résumé de la préface des Editeurs

Le hasard, assurent les éditeurs, a mis entre leurs mains ce petit opuscule écrit en français, dont ils ont fait faire une traduction par un philanthrope américain.

Les concepts émis par l'auteur en faveur des gens de couleur et des Noirs sont, à leur avis, extensibles à toute sorte de personnes. Les considérations énoncées et les exemples utilisés éveilleront donc chez tous, assurent-ils, les sentiments de piété et de dévotion, l'acceptation des souffrances et de l'adversité. Ils susciteront chez les enfants et les personnes soumises à autorité le respect dont ils doivent faire preuve envers leurs parents et leurs supérieurs, et chez ceux-ci leurs obligations et leurs devoirs envers ceux-là. C'est un ensemble de pensées morales tirées des Saintes Ecritures et des Pères de l'Eglise pour former l'homme à la vie spirituelle et le conduire au bonheur.

L'auteur ayant choisi avec délicatesse et savoir ces pensées qui correspondent davantage aux classes auxquelles il s'adresse, les éditeurs ne doutent pas qu'elles auront l'effet voulu dans les institutions créées dans leur pays pour l'éducation de ces mêmes classes.

\section{Commentaire}

La référence mise en exergue, tirée de l'Ecclésiastique, ne laisse aucun doute sur l'identité de l'auteur, jamais nommément citée. Elle constitue en effet le leitmotiv de l'œuvre de l'abbé Grégoire, auteur de l'article $1^{\mathrm{er}}$ de la Déclaration des Droits de l'Homme et du Citoyen adoptée par l'Assemblée constituante du 20 au 26 août 1789: «Les hommes naissent et demeurent libres et égaux en droits ». Prêtre jureur, Henri Grégoire fut nommé évêque constitutionnel de Blois en 1791, poste qu'il occupa dix ans. Honoré par l'empire, il fut déchu par la suite de sa dignité épiscopale en 1801, sous la pression de Rome lors de l'établissement du Concordat. Mort en 1831, il ne fut jamais réhabilité par la hiérarchie catholique, laquelle refusa d'ailleurs de participer à la «panthéonisation » de l'abbé en 1989.

On s'étonnera donc de voir cet opuscule approuvé par l'évêque de Buenos Aires quelques années seulement après le décès de l'ancien prélat. Medrano y Cabrera accorda même une série d'indulgences à ses lecteurs, «hommes de couleur et noirs ». Pour autant, la censure ecclésiastique, ou simplement l'autocensure, ne manqua pas d'imposer un principe de précaution, car le nom de l'auteur, à savoir « Grégoire », n'apparaît pas. Pourtant sa condition d'évêque est mentionnée, bien qu'elle fût canoniquement considérée comme nulle par Rome, non à la suite d'une prise de position schismatique, mais de la rupture de la continuité apostolique entre le successeur de Pierre et les évêques constitutionnels de l'église 
«nationale» non reconnus par le pape. Le nom du traducteur en castillan est également occulté. La page de titre se réfère à un «Sud-Américain » et, dans leur préface, les éditeurs précisent simplement qu'il s'agit d'un « philanthrope américain ».

Deux remarques à ce sujet. Il eût été normal, plusieurs années après l'indépendance de la vice-royauté du Río de la Plata, de voir apparaître une référence plus précise. Les éditeurs tenaient manifestement à préserver l'anonymat de ce traducteur. Il convenait peut-être aussi pour eux de ne pas trop attirer l'attention sur l'action de l'abbé Grégoire en faveur des Noirs d'Haïti alors que les anciennes possessions espagnoles n'avaient pas encore aboli l'esclavage des Noirs. C'était le cas de l'Argentine (abolition : $1^{\mathrm{er}}$ mai 1853), mais aussi d'autres pays comme la Colombie et l'Equateur (1851) ou le Venezuela et le Pérou (1854). Le traducteur est qualifié de «philanthrope », euphémisme qui signifiait pour l'époque un engagement personnel en faveur de l'abolition, d'où peut-être une autre raison de taire son identité. Le contraire aurait pu être contreproductif au regard de l'objectif fixé par la publication qui ne s'adressait pas aux esclaves, mais aux Noirs et gens de couleur sans autre précision. Pour s'en persuader, on se réfèrera à l'âpreté des débats sur l'abolition dans la vie parlementaire de ces pays, en particulier au Pérou où le parti conservateur faisait tout son possible en 1839 pour retarder l'octroi de la manumission pleine et entière aux libertos ${ }^{9}$, avec l'appui du président Agustín Gamarra $^{10}$. A Buenos Aires, le 2 février 1813, l'Assemblée Générale Constituante des Provinces Unies du Río de la Plata concéda la «liberté des ventres », selon laquelle tout enfant né d'une esclave obtiendrait sa liberté à l'âge de vingt-ans ${ }^{11}$. Il convenait donc d'éviter de se placer sur un terrain dangereux pour se limiter au domaine spirituel. Philanthropie, certes, mais aussi prudence bien ecclésiastique.

Point d'information non plus sur ces «éditeurs ». L’Apologie de Barthélémy de las Casas, évêque de Chiappa, discours lu le 12 mai 1800 devant l'Institut, puis publié par les éditions Baudouin, avait fortement impressionné de grands esprits latino-américains, comme Servando de Miers, le dominicain de la Nouvelle Espagne (Mexique) ${ }^{12}$. Il est probable qu'il ne fut pas

\footnotetext{
${ }^{9}$ Enfants d'esclaves dont on avait différé l'émancipation de vingt ans et que le droit de patronat soumettait à leurs anciens maîtres.

${ }^{10}$ Jean-Pierre Tardieu, El decreto de Huancayo. Abolición de la esclavitud en el Perú. 3 de Diciembre de 1854, Lima, Fondo Editorial del Congreso de la República, 2004.

${ }^{11}$ Marta B. Goldberg, «Los negros de Buenos Aires », in Luz María Martínez Montiel (coord.), Presencia africana en Sudamérica, México, Consejo Nacional para la Cultura y las Artes, 1995, p. 545.

${ }^{12}$ Voir : Bernard Plongeron, «Apologie de Barthélémy de Las Casas, Evêque de Chiapas, par le citoyen Grégoire », in Yves Bénot et Marcel Dorigny (éd.), Grégoire et la cause des Noirs (1789-1831). Combat et projets, Paris, Société française d'histoire d'outre-mer / Association pour l'Etude de la Colonisation Européenne, 2000, p. 49-50.
} 
le seul, sujet qu'il serait intéressant de développer ${ }^{13}$. Ce dont on est sûr, c'est que ces «éditeurs » connaissaient l'ouvrage dont nous traitons dans sa seconde édition. Grâce peutêtre à quelques-uns de ces nombreux Français résidant au Río de la Plata et en particulier à Buenos Aires ${ }^{14}$, sous les deux mandats présidentiels de Juan Manuel de Rosas (1829-1832; 1835-1852) qui d'ailleurs n'avait pas de très bons rapports avec leur mère patrie ${ }^{15}$. Entre 1838 et 1840, une escadre française fit même le blocus de Buenos Aires afin d'obliger le gouvernement à signer un accord commercial avec la France, rivale de l'Angleterre. Dans leur correspondance avec leurs supérieurs, les agents consulaires français dénonçaient la barbarie régnant dans la capitale ${ }^{16}$. Les recensements de 1836 et 1838 indiquent que $25 \%$ des habitants étaient encore noirs ${ }^{17}$. L'attitude populiste de Rosas l'amenait à vouloir les encadrer afin d'appuyer sa politique fédérative ${ }^{18}$. Il avait recours à des Afro-Argentins pour terroriser ses ennemis et exprimer la force populaire du «Restaurateur des Lois ». Pour ce faire, il encourageait les organisations propres aux Noirs qui jouèrent un rôle politique important ${ }^{19}$. Une partie de l'opinion publique, adverse aux visées de Rosas, se plaignait de la barbarie de ces foules, comme l'écrivain « unitaire » Esteban Echeverría (1805-1851). Dans El matadero (1838-1840), cet auteur dépeint le Noir «comme un être dégradé par l'ignorance, le despotisme [de Rosas] et la misère $»^{20}$. Les propositions de l'abbé Grégoire font donc partie d'un plan de régénération de l'âme et du comportement social du Noir ${ }^{21}$ qui dut être le

\footnotetext{
13 Alyssa Goldstein Sepinwall n'est guère explicite quant à ces relations. Elle fait allusion probablement à Servando de Miers en évoquant le Mexique et parle également de Bogotá et du Guatemala dont certains intellectuels avaient des relations avec l'abbé, sans donner toutefois de noms. Grégoire, affirme-t-elle, suivait avec grand intérêt les efforts de la nouvelle république de Colombie pour abolir l'esclavage, ce qui lui paraissait être un sage chemin pour prévenir la violence. Voir : The Abbé Grégoire and the French Revolution. The Making of Modern Universalism, University of California Press, 2005, p. 168-169.

${ }^{14}$ En 1839, selon les estimations, 4000 Français vivaient dans la province de Buenos Aires. Voir : José Manuel Azcona Pastor, Possible paradises. Basque emigration to Latin America, Reno, University of Nevada Press, 2004.

${ }^{15}$ Roberto Pablo Payró, El Río de la Plata : de colonias a naciones independientes. De Solís a Rosas, 1516 1852, Buenos Aires, Alianza Editorial, 2006, p. 543.

${ }^{16}$ Clara María Avendaño Marín, «Les agents français dans la Plata. L’impact des stéréotypes de la barbarie rosista pendant le blocus du port de Buenos Aires. 1838-1841 », Amerika [en ligne] 4 / 2011, mis en ligne le 18 décembre 2011, consulté le 30 avril 2016. CRL : http://amerika.revues.org/2172;DOI:10.4000/amerika.2172.

${ }^{17}$ Marta B. Goldberg, op. cit., p. 529.

${ }^{18}$ Id., p. 628.

${ }^{19}$ María Elena Vela, «Los afroamericanos en el imaginario de algunos intelectuales argentinos del siglo XIX », in Rina Cáceres (comp.), Rutas de la esclavitud en África y América Latina, San José de Costa Rica, Asociación pro-historia centroamericana, 2001, p. 413.

${ }^{20}$ Id., p. 593.

${ }^{21}$ Pour en savoir plus sur le problème de l'ambiguïté du concept de « régénération » chez l'abbé Grégoire, on consultera : Alyssa Goldstein Sepinwall, «Grégoire et Haiii : un héritage compliqué », in Yves Bénot et Marcel Dorigny (éd.), Grégoire et la cause des Noirs (1789-1831. Combat et projets, op. cit., p. 109-128; Mayyada Kheir, «L'Abbé Grégoire dans son temps », Archives de sciences sociales des religions [En ligne] ; 138 | avril juin 2007, mis en ligne le 17 septembre 2007, consulté le 20 mai 2016. URL : http://assr.revues.org/5072 ; DOI : 10.4000/assr.5072, p. 2-3. Grégoire parle plus précisément de « révolution morale » dans La noblesse de la peau
} 
bienvenu à Buenos Aires dans certains milieux. Ce qui est étrange, c'est que Rosas ne s'opposa pas à la publication de cet opuscule, peut-être parce qu'il ne l'estimait pas dangereux pour sa politique ou qu'il y voyait même un aspect positif pour ses propres objectifs.

\section{2-Analyse}

\section{2-1-L'exorde (p. 1-15)}

L'auteur ${ }^{22}$, dans son introduction s'adresse aux «Hommes de couleur et aux Noirs », sans précision ni de lieu ni de condition. Les éditeurs n'ont pas édulcoré son discours pour l'adapter à la situation de leur pays, où régnait encore l'esclavagisme avec le patronat sur les libertos. On divisera ce texte en neuf points qui résumeront l'exhortation.

a-Il traite ses destinataires, selon la terminologie conventionnelle, de « frères en JésusChrist », et s'appuie sur la prière du Notre Père pour affirmer que tous les hommes sont fils d'un même père ${ }^{23}$, ce qui relève aussi de la Nature. Le Nouveau Testament, est-il souligné, proclame que Dieu a fait naître d'un seul homme toute la race des hommes (Ac 17, 26), ce qui avait été d'ailleurs annoncé dans l'Ancien Testament (p. 2). L'apologie de l'esclavage ne peut donc s'appuyer sur les Ecritures, ce que certains ont fait par erreur et ambition. Il suffit de se reporter aux maximes évangéliques pour déceler l'aspect criminel de ces tentatives (p. 3).

b-La religion chrétienne est le seul moyen de parvenir à la félicité terrestre et céleste, car, à la différence de la loi civile, elle crée la vertu et le remord. Dieu s'est incarné en Jésus-Christ pour racheter le genre humain par ses souffrances et sa mort, de sorte que l'homme ne peut faire le bien sans l'intervention de la grâce divine (p. 4). Il faut donc s'en montrer digne. Mais le monde incrédule ne manque pas de sophismes pour combattre la religion ${ }^{24}$, et l'ignorance

(1826), in L'abbé Grégoire, Ecrits sur les Noirs, Présentation de Rita Hermon-Belot, Paris, L’Harmattan, vol. II, p. 167.

${ }^{22}$ C'est le terme que nous emploierons dorénavant, puisque l'identité de l'abbé Grégoire n'est pas ouvertement révélée.

${ }^{23}$ Dans Epitre des évêques réunis à Paris aux pasteurs et aux fidèles des colonies françaises (1798), il est écrit : «Ecoutez, nos très chers frères, écoutez la religion dont ils sont les ministres ; c'est elle-même qui vous crie : "Quels que soient la couleur ou le parti qui vous distingue, n'êtes-vous pas tous enfants du même père ? n'êtesvous pas tous citoyens de la même patrie" »; in L'abbé Grégoire, Ecrits sur les Noirs, op. cit., vol. I : 17891808, p. 80. Pour la dimension chrétienne de l'engagement de l'abbé en faveur de l'abolition, on consultera : Rita Hermon-Belot, «Grégoire et l'universalité des principes: les fondements chrétiens de son combat abolitionniste », in Yves Bénot et Marcel Dorigny (éd.), Grégoire et la cause des Noirs (1789-1831). Combat et projets, op. cit., p. 26-36.

${ }^{24}$ L'évêque constitutionnel se montra toujours ferme sur cet aspect face à ses dénigreurs, comme il apparaît dans l'Epitre des évêques réunis à Paris... : «En vain l'athéisme, traînant à sa suite tous les forfaits, se flatte 
ne permet pas de réfuter ses faux raisonnements ou ses tentatives de ridiculiser la piété. Seront-ils de quelque secours devant le tribunal suprême ? Or jamais personne ne s'est repenti de s'être comporté en bon chrétien. Cela incite à vivre comme on aurait aimé avoir vécu au moment de la mort (p. 5-6).

c-L'attitude d'un pasteur pénétré de la sainteté de ses fonctions donne à réfléchir au plus mauvais. Et dans l'Afrique portugaise, des hommes de couleur et des Noirs se sont distingués comme prêtres et comme évêques ${ }^{25}$. Le temps n'est pas loin où l'on ouvrira des séminaires pour former des aspirants au sacerdoce de toutes les couleurs (p. 7).

d-Car la religion n'offre pas une simple satisfaction de l'esprit, « une brillante théorie »: elle impose de profonds sacrifices. L'apôtre Jacques rappelle que la foi sans les œuvres n'est d'aucune utilité (2, 14-17). Selon le schéma classique élaboré par saint Paul, l'auteur insiste sur le véritable esclavage, à savoir celui du péché : impudeur, vanité, paresse, colère, avarice. Il ne suffit pas de ne point commettre des actes délictueux pour être à l'abri de tout reproche, comme l'illustre la parabole des talents ou celle de l'homme riche. Nous sommes responsables de nos talents face à Dieu (p. 8) : on ne peut être chrétien à moitié.

e-Dans les pays où a sévi l'esclavage, une « absurde préoccupation », malgré les préceptes de la religion et les lois de la nature, fait obstacle au mariage entre gens de couleur différente, d'où l'apparition du libertinage qui suscite le scandale par des unions illégitimes ${ }^{26}$. Seul le sacrement du mariage sanctifie l'union des époux, et il requiert, pour le mériter, l'état de grâce, brisé par l'infidélité. Le concubinage prépare les enfants au scandale (p. 9). Il revient aux épouses et aux mères de purifier les mœurs par leurs exemples en résistant à la frivolité des modes, selon l'enseignement de saint Paul (1 Tm, 2, 9 et suivants). Dans la vertu des

d'établir son odieux empire sur les ruines de nos temples et les débris de nos autels ; en vain il emprunte la voix d'une fausse philosophie pour chanter ses honteux et funestes succès... »; op. cit., vol I, p. 67.

${ }^{25}$ L'abbé Grégoire revint plusieurs fois sur cet aspect dans ses œuvres. Il y est fait allusion dans l'Epitre des évêques réunis à Paris..., op. cit., vol. I, p. 70, et dans le chapitre 2 de De la littérature des Nègres (1808), in Ecrits sur les Noirs, op. cit., vol. I, p. 141. Même s'il avait raison sur le principe, l'application était loin d'être généralisée.

${ }^{26} \mathrm{C}$ 'est là un thème préoccupant pour l'abbé Grégoire, qui ressort à maintes reprises sous sa plume. Dans Mémoire en faveur des gens de couleur ou sang-mêlés de Saint-Domingue et des autres îles françaises de l'Amérique, adressé à l'assemblée nationale (1789), in Ecrits sur les Noirs, op. cit., vol. I, p. 28, il propose de punir le concubinage. Dans Des peines infamantes à infliger aux négriers (1822), il fustige la «noblesse de l'épiderme » qui «flétrit le mariage d'un Blanc avec une femme de couleur, fût-elle un modèle de vertu, tandis qu'elle n'inflige pas même le mépris au libertinage le plus éhonté »; in Ecrits sur les Noirs, op. cit., vol. II, p. 47. Il y revint enfin avec virulence dans l'Epitre aux Haïtiens (1827) : «J'ai flétri le concubinage exporté en Amérique par les Européens, plaie infecte et hideuse qui est encore, parmi vous, une source de scandales ... »; in Ecrits sur les Noirs, op. cit., vol. II, p. 184. On pourrait citer d'autres exemples. 
mères, les enfants lisent ce qu'ils doivent faire : elle leur permet d'éviter la dépravation (p. 10). A quoi leur serviront les richesses si on ne leur a pas enseigné à en faire un bon usage ? ${ }^{27}$ C'est dans l'enfance que l'on apprend les mauvaises habitudes. L'ignorance fait de l'homme l'objet de ses passions.

f-Ceux qui sont appelés à jouir des droits du citoyen doivent également en assumer les devoirs. L'expérience prouve que les hommes de couleur et les Noirs ont en eux d'heureuses dispositions pour développer tous les talents ${ }^{28}$, ce qui suppose de faire passer le cœur avant l'esprit (p. 11-12).

g-L'homme est jugé par Dieu à l'aune de son amour pour ses semblables. Cela doit amener les récepteurs de ce discours à résister aux divisions que leurs ennemis tentent d'introduire entre eux sous prétexte de diversité de couleurs. La vanité, l'orgueil sont des signes de la dépravation du cour. Qu'avez-vous, demande l'Apôtre, que vous n'ayez reçu, et si vous l'avez reçu, pourquoi vous en glorifiez-vous comme si vous ne l'aviez pas reçu ? (1 Cor, 4, 7). Le chrétien doit respecter les lois, même si elles semblent rigoureuses ou imparfaites, car elles sont l'expression de la volonté générale, à laquelle concourent ses représentants (p. 13-14).

h-La prise en considération de ces préceptes permettra de résister à toutes les impostures et à la malveillance qui veulent refuser aux Africains et à leur descendance les talents et les vertus dont ils ont tant de fois donné des preuves remarquables (p. 14-15).

i-En conclusion, l'auteur se présente comme un homme qui peut se tromper, mais ne trompera jamais ses interlocuteurs,

un homme qui après trente-quatre ans, calomnié, poursuivi sans interruption pour avoir défendu votre cause, qui est celle de la justice, n'ouvrit jamais son cœur au ressentiment, ne conserve aucune animosité contre ses ennemis, et qui, arrivé au soir de sa vie,

\footnotetext{
${ }^{27}$ Autre sujet de prédilection de l'abbé Grégoire qui apparaît par exemple dans De la liberté de conscience et de culte à Haïti (1824) : "L'Ecriture sainte dit : Tu as un fils, instruis-le; elle ne dit pas, enrichis-le ; et à quoi lui serviraient les richesses, s'il n'a pas appris l'art d'en faire un saint usage ? »; in Ecrits sur les Noirs, op. cit., vol. II, p. 136. Il est à remarquer qu'il reprend les mêmes paroles dans son Manuel de piété...Précisons, s'il le faut, qu'il n'était pas encore question de s'enrichir pour les afro-argentins !

${ }^{28}$ C'est l'un des principaux thèmes des écrits de l'abbé en faveur des Noirs. Voir : De la littérature des Nègres ou recherches sur leurs facultés intellectuelles, leurs qualités morales et leur littérature, suivies de notices sur la vie et les ouvrages des Nègres qui se sont distingués dans les sciences, les lettres et les arts (1808), in Ecrits sur les Noirs, op. cit., vol. I, p. 103-226.
} 
consentirait à être victime des calomnies et de nouvelles persécutions, s'il pouvait ainsi contribuer à [leur] bonheur (p. 15) ${ }^{29}$.

\section{Commentaire}

Le premier point récuse la justification de l'esclavage, bien souvent fondée sur des motifs religieux en effet (accès à la véritable foi et donc au salut), et le troisième montre qu'on n'a pas besoin d'y avoir recours pour faire de bons chrétiens. Il s'agit donc de préparer ces interlocuteurs à leur futur rôle de citoyens dans la société. C'est là qu'intervient la religion chrétienne, seule capable, estime l'auteur, d'offrir l'instruction adéquate afin de résister aux arguments de l'adversaire qui fera tout pour maintenir les hommes de couleur et les Noirs dans la dépendance en les divisant entre eux grâce à la prégnance sociale de la hiérarchie des couleurs, laquelle plonge ses victimes dans la négation d'une véritable vie familiale avec les frustrations voire les vices que cela suscite. Jusqu'à présent, on retrouve les préoccupations séculaires de l'Eglise pour toutes les Amériques espagnoles. Mais, ajoute l'auteur, l'éducation familiale chrétienne peut former un bon citoyen, car la reconnaissance de droits suppose celle de devoirs librement acceptés, même si la législation est imparfaite. Cet aspect n'était pas applicable en Argentine, encore éloignée du moment où les représentants des hommes de couleur et des Noirs allaient pouvoir légiférer. D'autre part les tensions raciales entre Mulâtres et Noirs furent un problème bien particulier à l'ancienne Saint-Domingue française peu avant son indépendance. Et que dire de l'application au Río de la Plata du développement sur la relation éducation / richesse ? Les Noirs de cette région étaient bien loin d'y prétendre ! L'usage stricto sensu de ce texte est donc souvent impropre dans le contexte choisi, ce dont les éditeurs ne se préoccupèrent pas.

Bref, l'homme de couleur est tout à fait capable d'être responsable de lui-même. L'esclavage est une situation créée par la cupidité, la vanité et l'orgueil, mais pour sortir de la mentalité qu'il a créée, ses victimes doivent passer par la régénération du christianisme. Voilà donc la substantifique moelle de ce discours. A la fin de toute une vie de lutte, l'auteur confie son amertume face aux attaques subies pour avoir défendu ce qu'il faut ramener en définitive au message évangélique, perverti par le péché. Il s'agit d'un véritable testament où il

\footnotetext{
${ }^{29}$ Notre traduction. L'abbé ne cacha pas que les calomnies dont il faisait l'objet l'avaient profondément blessé, sans toutefois le décourager. Dans De la noblesse de la peau (1826), il écrivit : «La fureur coloniale traita de provocation ce qui n'était que prévision, qu'espérance pour un temps indéterminé, et jusqu'à l'époque actuelle inclusivement, que de libelles, de calomnies, d'injures et de persécutions dirigées contre l'auteur »; in Ecrits sur les Noirs, op. cit., vol. II, p. 168.
} 
démontre sa totale orthodoxie dans ce qui a été l'essentiel de son combat, réponse aux accusations dont il a pu faire l'objet, et proclame sa foi en l'avenir, sans faire pour autant preuve d'irénisme, car il croit en l'homme et dans l'humanisme chrétien. A la vérité les destinataires de l'opuscule ne se trouvaient pas à même de saisir la portée de cet ultime plaidoyer pro domo, qui ne se justifiait absolument pas dans le contexte argentin.

\section{2-2-Le recours aux Saintes Ecritures (p. 16-25)}

Pour étayer son discours, l'auteur consacre une partie de son ouvrage (p. 16 à 25) à développer les références bibliques rapidement citées dans l'exorde, au sujet de l'unique origine de l'homme descendant d'Adam, racheté par le sacrifice du Christ, et de l'injure au créateur qu'est le mépris de l'homme pour le pauvre. L'iniquité ne peut rester ignorée de Dieu. Le baptême en un seul esprit fait de tous les hommes un seul corps, quelles que soient leur origine, leur race et leur condition, ce qui implique l'amour de l'un pour l'autre.

La vente d'un homme par un autre homme est un délit puni sévèrement par l'Ancien Testament. D’ailleurs il y est recommandé aux Hébreux de libérer leurs esclaves tous les sept ans, en commémoration de leur délivrance par Dieu de la domination des Egyptiens. De même, afin de mériter la miséricorde divine, il ne faudra pas affliger l'étranger, l'orphelin, la veuve, opprimer autrui injustement et verser le sang des innocents. Le serviteur aura à cœur de servir son maître avec amour, et celui-ci le traitera avec affection, car ils ont le même père. L'esclavage n'est en réalité qu'une convention : l'homme a été racheté par les souffrances du Christ. Son sacrifice doit servir d'exemple : il n'a pas répondu au mal par le mal. Comme membres de son corps, les chrétiens doivent faire preuve de charité les uns envers les autres, assumer leurs devoirs en s'aidant de la prière, bénir leurs persécuteurs, rechercher la paix avec humilité en renonçant à la vengeance et en portant secours à leurs ennemis, fuir la fornication et l'adultère. En définitive il convient de vivre en ce monde comme si on n'y appartenait pas, car la vie sur terre est courte et toutes les afflictions concourront à notre gloire dans l'au-delà.

Comme on le voit, il s'agit en fait dans ce chapitre de faire un résumé accessible aux gens modestes (appelés autrefois les «rudes ») de l'enseignement chrétien qui ne se fonde pas sur des réalités terrestres fugaces, et de leur donner de l'espoir. Ce discours, authentiquement christiano-centrique, met l'accent sur l'injustice de l'esclavage au regard de la loi divine, ce qui peut paraître encore osé au regard de la situation en Argentine, mais cela est aussitôt tempéré par l'appel à l'acceptation de son sort, qui a un autre sens qu'en Haïti où l'esclavage n'existe plus. 


\section{2-3-Considérations sur l'Afrique (p. 26 à 34)}

Même s'ils se trouvent loin de leur continent d'origine, rappelle l'auteur, les Africains et leurs descendants doivent savoir que c'est en Afrique que la foi chrétienne s'est illustrée pour la première fois, en particulier en Egypte. L'Ethiopie a connu très tôt les Evangiles, et par la suite le christianisme s'est répandu en Afrique, où ont été fondés des sièges épiscopaux occupés par d'illustres prélats, docteurs de l'Eglise, dont l'auteur cite les noms, et où se sont déroulés des Conciles qui servent toujours de références.

Cette Afrique a été ensuite déchirée par les hérésies et les schismes, dont ont souffert de nombreux martyrs. Cela a duré jusqu'au cinquième siècle où les Vandales ont fait des ravages, aspect sur lequel l'auteur s'attarde à travers des exemples précis. Puis vinrent les invasions des Sarrazins, qui ont initié la vente d'esclaves, commerce qui s'est perpétré jusqu'à l'époque contemporaine avec l'intervention de marchands d'êtres humains pour le plus grand mépris des lois divines et humaines ${ }^{30}$.

Mais si l'Eglise, châtiment de la turpitude de ses adeptes, s'est vu obligée d'abandonner ces contrées où le christianisme prospérait, elle a réussi à pénétrer dans d'autres. Elle est toujours présente cependant sur le continent africain dans les établissements soumis à des puissances européennes catholiques, comme le Portugal, où des Noirs ont accès au sacerdoce. La Congrégation de Propaganda Fide y envoie des missionnaires, et le cardinal Cibo leur a demandé en 1683 de prêcher contre la traite des Noirs en pesant de tout leur poids ${ }^{31}$. Il reste à espérer que la miséricorde divine s'étende à travers tous ces territoires dont sont issus les gens auxquels s'adresse l'auteur.

Point n'est besoin d'insister sur sa volonté de leur rendre leur dignité en rappelant les origines du christianisme, même si, en réalité, les faits exposés, mis à part l'Ethiopie, se déroulaient en Afrique du Nord. Mais en Afrique noire, les espoirs ne manquent pas, assure-til. S'il n'eut cesse de le faire ailleurs ${ }^{32}$, il n'insiste cependant pas ici sur l'implication des

\footnotetext{
${ }^{30}$ Dès le chapitre premier de Des peines infâmantes à infliger aux négriers (1822), l'abbé proclame : «La traite est un attentat contre la loi naturelle, qui défend de faire à autrui ce que nous ne voulons pas qu'il nous soit fait »; in Ecrits sur les Noirs, op. cit., vol. II, p. 45.

${ }^{31}$ En 1822, dans Des peines infâmantes à infliger aux négriers, l'abbé reconnaît le rôle du cardinal Cibo qui, par l'intermédiaire de Propangada Fide, «enjoignit aux missionnaires d'Afrique de prêcher contre l'usage de vendre des hommes ». Il précise qu'il a lui-même écrit en 1818 à son successeur, le cardinal Fontana, afin que la Congrégation, «par un décret solennel publié dans toutes les régions, [réitère] à tous les missionnaires l'injonction de prêcher contre le crime de vendre les hommes ». Dans la même lettre, il lui promit de lui envoyer son Manuel de piété à l'usage des hommes de couleur et des Noirs ; in Ecrits sur les Noirs, op. cit., vol. II, p. 6163.

${ }^{32}$ Dans De la littérature des Nègres (1808), par exemple : «Depuis trois siècles, l'Europe, qui se dit chrétienne et civilisée, torture sans pitié, sans relâche, en Amérique et en Afrique, des peuples qu'elles appelle sauvages et barbares. Elle a porté chez eux la crapule, la désolation et l'oubli de tous les sentiments de la nature, pour se procurer de l'indigo, du sucre, du café »; op. cit., vol. I, p. 223.
} 
puissances chrétiennes dans le commerce de l'être humain, ce qui lui paraissait probablement contre-productif dans l'optique choisie pour ce chapitre. Il s'agissait pour lui en définitive de redonner une identité, forcément chrétienne, à ces hommes de couleur et à ces Noirs appelés à fonder une nouvelle nation à Haïti, quitte à aller un peu vite en besogne ${ }^{33}$. Si ce n'était pas le cas en Argentine, ce dont les éditeurs ne pouvaient qu'être conscients, il importait toutefois à leurs yeux d'y consolider cette identité chrétienne des Noirs, étant donné la situation dans laquelle ils se trouvaient.

\section{2-4-Du culte des saints en général et de ceux d'Afrique en particulier. Litanie des} saints. Prières (p. 34-48)

Après avoir évoqué les premiers temps de l'Eglise en Afrique, l'ouvrage propose à la vénération (et non à l'adoration) de ses destinataires des exemples de sainteté tirés de l'histoire de ce continent. S'il n'y a qu'un seul médiateur, Jésus-Christ, les saints peuvent intercéder en faveur des hommes auprès de lui. Il est donc bon de les prier et de les imiter ou du moins de s'inspirer de leur conduite. Tous les chrétiens ont vocation à devenir saints, y compris les récepteurs de ce discours.

L'appartenance à une confrérie et la participation aux pèlerinages offrent l'occasion d'exprimer cette vénération, même si elles ne sont pas des gages absolus, car les pratiques extérieures ne se substituent pas à la vertu. Il ne faut pas seulement prier les saints, mais les imiter. L'Amérique n'en manque pas avec saint Toribio, archevêque de Lima, sainte Rose, également de Lima $^{34}$ et patronne de nombreuses paroisses à Haïti. Le sort des esclaves a motivé l'action de grands saints comme Pierre Nolasque ${ }^{35}$, fondateur de l'ordre de la Merci pour le rachat des captifs, Jean de Matha et Félix de Valois ${ }^{36}$, instaurateurs des Trinitaires chargés d'une mission identique, et Vincent de Paul ${ }^{37}$, qui se consacrait à la libération des prisonniers. Et tous les personnages qui ont dédié leur vie à défendre la cause des esclaves ne sont pas canonisés, comme les jésuites Vieira et Claver $^{38}$ pour les Noirs, et les dominicains

\footnotetext{
${ }^{33}$ Grégoire rappelle dans De la littérature des Nègres (1808) que Toussaint Louverture avait rétabli le culte à Saint-Domingue et qu'il entretint avec lui une correspondance « dont le but était d'obtenir douze ecclésiastiques vertueux », même s'il « lui suscita des tracasseries » plus tard ; op. cit., vol. I, p. 149.

${ }^{34}$ Saint Toribio de Mogrovejo (1538-1601). Sainte Rose (1586-1617), de bonne famille liménienne, se distingua par ses mortifications.

${ }^{35}$ Religieux catalan (1180 / 1182-1245).

${ }^{36}$ Jean de Matha (1160-1213) ; Félix de Valois (1127-1212).

${ }^{37}$ Saint Vincent de Paul (1581-1660) fut lui-même capturé par les barbaresques et réduit en esclavage à Tunis.

${ }^{38}$ Le jésuite saint Pierre Claver (1580-1654) fut le successeur d'Alonso de Sandoval dans le « ministère » des Noirs à Carthagène des Indes, en Colombie actuelle, qui consistait à prendre en charge l'accueil et l'évangélisation des esclaves débarqués dans ce port avant d'être répartis dans toute la vice-royauté de Lima. António Vieira (1608-1697), également jésuite, est connu pour ses prédications auprès des esclaves du Brésil.
} 
Barthélémy de las Casas ${ }^{39}$ et Antoine de Montesinos ${ }^{40}$ pour les Indiens. L'Afrique offre de prestigieux exemples avec saint Elesbaan, roi d'Ethiopie, le bienheureux Antoine de Caltagirone, et saint Benoît le Maure, canonisé en $1807^{41}$. Il est bon de donner leur nom aux enfants et aux nouvelles paroisses.

Notons encore une fois la volonté de l'auteur d'impliquer les destinataires de son discours, par des références à leur continent d'origine ou à leur propre vie, prémices de la future méthode d'inculturation en matière de christianisme qui avaient leur utilité dans toutes les Amériques, dont l'Argentine. S'il y a eu l'esclavage, sur les causes duquel l'auteur ne s'arrête pas ici, il insiste par contre sur les défenseurs de ses victimes dont l'action leur a valu la canonisation ou du moins la vénération des fidèles. D'ailleurs même des Africains ont été portés sur les autels, ce qui ne pouvait manquer d'être flatteur pour leurs congénères d'outreAtlantique. Cette partie du discours est aussi entièrement transposable aux afro-argentins.

L'ouvrage propose à la pratique de ses récepteurs une litanie des saints adaptée où apparaissent les personnages cités précédemment, comme saint Benoît de Palerme, le franciscain noir. Une adresse particulière est proposée en faveur de tous les saints «qui [ont] déployé tant de zèle, les uns pour soulager, racheter, libérer les captifs et les esclaves, les autres pour établir et faire triompher les droits des hommes réunis en sociétés ». Elle ne manque pas d'un certain intérêt discursif, car elle laisse apparaître dans son second mouvement, mais d'une façon orthodoxe, une tendance à la laïcisation du thème de la sainteté en relation avec le combat de l'abbé Grégoire en faveur des droits de l'homme.

Cette litanie est suivie d'une série de prières où se manifeste le désir de son concepteur d'affermir le lien de ces nouvelles communautés de chrétiens avec la chaire de Pierre, les pratiques chrétiennes chez ces néophytes, leur reconnaissance pour avoir été libérés de l'esclavage - la véritable liberté étant cependant celle de l'esprit -, la conscience de leur dignité d'hommes, de citoyens et de chrétiens, élément trinaire capital aux yeux de l'auteur pour définir le nouvel homme afro-latino-américain. Mais il y a plus. Fort de la troisième dimension de cette dignité fraîchement acquise, il se doit, à l'exemple du Christ, de pardonner à ses persécuteurs et de leur rendre le bien pour le mal. On voit aisément l'implication politique pour le cas d'Haïti, mais le lien peut être facilement établi avec les autres pays du

\footnotetext{
${ }^{39}$ Grégoire fut l'un des premiers à réfuter les accusations portées contre Las Casas d'avoir favorisé la traite des Noirs, ce qui a du poids, venant de sa part. Voir Apologie de Barthélémy de las Casas, évêque de Chiappa (1800), in Ecrits sur les Noirs, op. cit., t. I, p. 87.

${ }^{40}$ Les sermons du dominicain Antonio de Montesinos furent pour beaucoup dans la prise de conscience de Bartolomé de las Casas.

${ }^{41}$ Saint Elesbaan et saint Benoît le Maure (ou de Palerme) sont cités dans De la littérature des Nègres..., op. cit., vol. I, p. 139-140.
} 
Nouveau Monde où a sévi l'esclavage, c'est-à-dire dans tous. Une telle adjuration participe de la régénération de l'homme de couleur évoquée plus haut, d'autant que l'auteur rappelle que l'esclavage perdure. Cela l'amène à inciter ses victimes à la patience et à la résignation, en accord avec ce que j'ai appelé ailleurs la «théologie de la résignation ${ }^{42}$. Voilà qui semble contradictoire à première vue, sauf si l'on sait que l'abbé a été partisan du gradualisme en matière d'abolition.

En écho à la valorisation du passé chrétien de l'Afrique, l'auteur exhorte ses lecteurs à prier pour leurs congénères se trouvant dans «les ténèbres de l'idolâtrie et du mahométanisme ». Comment les liens du sang pourraient-ils les laisser insensibles à cette situation? Cette proposition n'offre donc aucune rupture avec son temps.

L'une des préoccupations, latente, de toute cette œuvre relève davantage du cas haïtien. Il s'agit des rivalités entre hommes de couleur et Noirs, dont l'auteur a perçu le danger pour l'avenir de la nouvelle république. Il est d'abord amené à prier Dieu d'éteindre chez ses lecteurs «ces funestes dissensions », «quelle que soit leur couleur », négation du principe de charité, au sens chrétien du terme ${ }^{43}$. Mais il étend cette règle d'amour, consubstantielle au christianisme, «à tous nos frères qui existent dans les ténèbres de l'erreur et de l'hérésie ». Allusion à l'existence de pratiques religieuses ancestrales (vaudou, probablement), à leur mélange avec le christianisme et même à l'introduction d'autres confessions chrétiennes (méthodisme), ce qui était effectivement le cas à Haïti, mais certes bien moins en Argentine où, héritage du passé, l'orthodoxie catholique était surveillée de près. L'auteur recommande à ses lecteurs de favoriser l'amendement de leurs semblables par les bonnes ouvres et l'exemplarité de leur conduite.

L'avenir d'Haïti dépend du labeur de ses citoyens : on sait que Toussaint Louverture s'est évertué à les remettre au travail, concept lié pour eux à la servitude. L'auteur en est conscient, et rappelle la dimension chrétienne de «l'amour du travail » ${ }^{44}$. Mais il ne méconnaît pas les responsabilités des dirigeants politiques dans ce pays en proie à la violence, même s'il n'y fait pas directement allusion. C'est pour cette raison qu'il suggère à ses habitants d'invoquer en leur faveur «l'esprit de sagesse ", car ils ne mériteront le bonheur éternel qu'après avoir participé par leur action à celui de leur «patrie terrestre». Cette proposition était aussi

\footnotetext{
${ }^{42}$ J.-P. Tardieu, L'Eglise et les Noirs au Pérou. XVI $-X V I I^{e}$ siècles, op. cit.

${ }^{43}$ Dans De la littérature des Nègres (1808), l'abbé ne nie pas le fait que les Haïtiens s'entredéchirent et qu'ils «n'ont pu, jusqu'à présent, asseoir parmi eux une forme stable de gouvernement »; op. cit., vol. I, p. 175.

${ }^{44}$ Dans Considérations sur le mariage et sur le divorce, adressées aux citoyens d'Haïti (1823), Grégoire assure que « l'activité au travail [...] est le gardien des mœurs », et dans La noblesse de la peau (1826) que «l'amour du travail amènera la liberté civile »; in Ecrits sur les Noirs, op. cit., t. II, p. 119 et 167.
} 
extensible aux anciennes Amériques espagnoles qui se heurtaient à la résistance passive, voire active, des esclaves et des affranchis à l'aspect coercitif du travail.

Puis vient une proposition de prière, résumé en quelque sorte des différents points évoqués ci-dessus. Elle serait tout à fait conventionnelle s'il n'apparaissait cependant certaines formules significatives de la finalité recherchée par l'auteur. Il y est en effet exprimé le désir de voir ces hommes de couleur et ces Noirs - en l'occurrence les Haïtiens, mais ce souhait pouvait concerner toute l'Amérique et l'Argentine en particulier - devenir « les élus de Dieu par leur foi et leurs bonnes œuvres », faire partie «de son peuple», de façon à «échapper à l'instabilité des choses du monde ». Au terme de sa vie, l'avenir du peuple d'Haïti semble être l'objet de la grande crainte de l'auteur, car les menaces viennent aussi de l'extérieur. Est-ce une référence aux ambitions du puissant voisin du Nord ? Les éditeurs de l'opuscule argentin pouvaient la partager car l'instabilité, pour des causes différentes certes, menaçait également leur pays.

\section{2-5-Des saints africains (p. 49-59)}

L'auteur initie ce chapitre en émettant des doutes sur la véracité des faits rapportés par la tradition. Aussi ne s'appuiera-t-il que sur des certitudes historiques.

La sainteté de l'Ethiopienne Iphigénie lui semble de bon aloi puisqu'elle a été «instruite, baptisée et consacrée à Dieu par saint Matthieu ». Reconnue par le martyrologe romain pour sa résistance à toutes les tentations dont elle a fait l'objet, elle est principalement honorée en Italie, en Espagne et en Afrique où des «statues noires lui ont été érigées ».

Plus d'espace est consacré à saint Elesbaan, déjà évoqué dans l'opuscule. Roi des Ethiopiens d'Aksoum, ses possessions s'étendaient depuis les côtes occidentales de la mer Rouge jusqu'à l'intérieur du continent. Les chrétiens, persécutés par les Juifs de l'Arabie Heureuse (Arabie du Sud) dirigés par Dunaan, firent appel à l'empereur Justin l'Ancien qui sollicita l'aide d'Elesbaan en 523. Ce dernier, vainqueur, répara les torts causés, puis abdiqua pour se retirer dans un monastère où il mena une vie ascétique.

La notice sur le Mulâtre Martin de Porras, frère lai du couvent dominicain de Lima, est fort courte. Toutefois l'auteur, même s'il n'en fournit pas les motifs, n'ignore pas que ce personnage du $\mathrm{XVI}^{\mathrm{e}}$ et $\mathrm{XVII}^{\mathrm{e}}$ siècles (et non du XVIII ${ }^{\mathrm{e}}$ !) mérita de son vivant le plus grand respect de toute la société liménienne, y compris les plus hautes autorités. Au moment de la rédaction, il n'avait pas encore été proclamé bienheureux et sa canonisation dut attendre le $\mathrm{XX}^{\mathrm{e}}$ siècle. 
Deux bienheureux sont rassemblés dans une même notice. Antonio de Caltagirone, surnommé le «Saint Noir », est aussi communément appelé «l'esclave », car, né en Afrique dans les montagnes de Barca et fils de musulmans, il aurait été assujetti à Juan Frumentino de Caltanisella. Vendu en Sicile, il fut employé comme berger, tâche qui lui permit, après sa conversion, un dialogue solitaire avec Dieu et, lorsque cela lui était possible, d'œuvrer à la consolation des prisonniers. Une fois libre, il entra dans le tiers ordre franciscain à Caltagirone où il mourut en 1580 . On sait peu de choses de sa vie. Il n'est pas à confondre avec un autre bienheureux noir mort en 1549, Antoine de Noto, du même ordre et non moins célèbre, assure l'auteur.

Cette évocation se termine par le panégyrique de saint Benoît le Maure ou de Palerme, ville où il mourut en 1589. Fils d'esclaves, il avait été affranchi et, de berger lui aussi, il devint modeste agriculteur avant de rejoindre un groupe d'ermites dont il prit la tête. Sur ordre du pape, il rejoignit comme frère lai le tiers ordre des franciscains de Palerme où sa réputation de sainteté l'avait précédé. Malgré la modestie de son rang et de ses occupations à la cuisine, il fut élu gardien du couvent. A ce titre, il participa au chapitre provincial à Girgenti dont la population l'accueillit avec des acclamations. Devenu maître des novices à la fin de son mandat, il se comporta avec la plus grand humilité envers ses disciples. Sa réputation s'étendant, il était consulté par les évêques et même le vice-roi de Sicile, et ce dernier fut convaincu d'épargner la vie de son frère Marc, coupable de meurtre, non par son plaidoyer, que Benoît se refusa à prononcer, mais par l'humilité de ses paroles : «Faites ce que vous croyez juste ». Mort en odeur de sainteté, l'ensemble des habitants de Palerme assista à sa sépulture, et sa tombe attira des pèlerins de toute la Sicile. Sa vénération s'étendit jusque dans les provinces espagnoles et portugaises du Nouveau Monde, et on lui attribue une «multitude de miracles » qui lui valurent la canonisation en 1806. Bougainville, dans la relation de ses voyages, assure qu'à Buenos Aires une confrérie de Noirs s'est placée sous son invocation. Le traducteur de l'ouvrage précise que cette confrérie se trouve sous la protection non des dominicains mais des franciscains, ce qui paraît logique ${ }^{45}$.

Ainsi se termine ce petit opuscule, sur une note tout à fait classique. C'est un fait avéré que les différents ordres religieux de l'Amérique latine, dans leur approche des Noirs et des Mulâtres, esclaves ou hommes libres, ont tiré profit de la vénération dont faisaient l'objet ces personnages. Avec le temps, cela n'a fait que se développer, comme en attestent actuellement dans bon nombre de cités latino-américaines les activités des confréries placées sous leur

\footnotetext{
${ }^{45}$ Pour la dévotion à Buenos Aires envers saint Benoît, voir : Dina V. Picotti C., La presencia africana en nuestra identidad, Buenos Aires, Ediciones del Sol, 1998, p. 250.
} 
patronage. L'auteur, en l'occurrence l'abbé Grégoire, n'hésita pas à mettre à profit la tradition et les faits récents comme la canonisation de saint Benoît de Palerme, pour proposer aux hommes de couleur et aux Noirs d'Haïti des parangons de vertus dans un monde bien agité. Preuve d'une certaine crédulité de la part de cet homme des lumières ? Après tout, il ne renonça jamais à son état religieux, malgré ses difficultés. Mais ne faut-il pas voir plutôt dans ce recours un moyen d'encadrer certaines dérives dans la vie du pays qui l'inquiétaient et risquaient de menacer son œuvre de législateur? La décision de ses éditeurs à Buenos Aires, tint sans doute d'une motivation semblable, même si la situation était loin d'être identique à celle d'Haïti. Souvenons-nous des descriptions d'Esteban Echeverría.

Ce manuel de piété, presque anonyme, propose, en accord avec son époque, une régénération de l'homme de couleur et du Noir manifestement destinée à Haïti. Ses éditeurs argentins, sans prendre garde aux risques d'impropriétés voire d'anachronismes ou les minimisant volontairement, en proposèrent l'utilisation intégrale pour leur région à titre d'adjuration. L'abbé Grégoire ne fait-il pas remarquer dans un de ses derniers ouvrages, Epitres aux Hä̈tiens (1827), que « dans le nouveau monde, cinq millions d'esclaves soulèvent leurs fers en invoquant le Ciel et la Terre contre la férocité des bourreaux à figure blanche » $?^{46}$ Cette petite œuvre fait apparaître les craintes de l'auteur pour l'avenir d'Haïti en proie aux dissensions internes et aux menaces de l'extérieur. Pour lui la régénération chrétienne est un moyen de les conjurer. L'on comprend donc plus facilement les raisons prospectives, quoique souvent hâtives, des éditeurs argentins de faire traduire et de publier cet opuscule dans une époque de troubles où, grave menace pour la paix civile, le sort des Noirs de leur pays laissait beaucoup à désirer et le problème de leur condition n'avait pas encore été réglé.

\footnotetext{
${ }^{46}$ Ecrits sur les Noirs, op. cit., vol. II, p. 189.
} 


\section{Annexe}

Les quatre gravures de l'édition argentine sont fort semblables à celles de l'édition parisienne de 1822, au nombre de six. Cependant, il en manque deux : celle qui représente le mariage par un évêque d'un Blanc et d'une Noire - sacrement auquel tenait particulièrement l'abbé Grégoire -, et celle où l'on voit, si l'on en croit la légende, un planteur à l'article de la mort affranchir ses esclaves. La première était sans doute osée pour le contexte local. Il ne semble pas que ce fût le cas pour la seconde - qui n'était d'ailleurs plus d'actualité pour Haïti - car c'était une pratique courante aux Amériques espagnoles. Mais on devait craindre peutêtre qu'elle n'avive les revendications des esclaves.

Les éditeurs n'étaient donc pas en mesure d'aller aussi loin que l'abbé Grégoire, qui avait dû cautionner l'insertion de ces gravures dans son manuel, la situation d'Haïti étant plus évoluée à ce sujet que celle de la république argentine. 


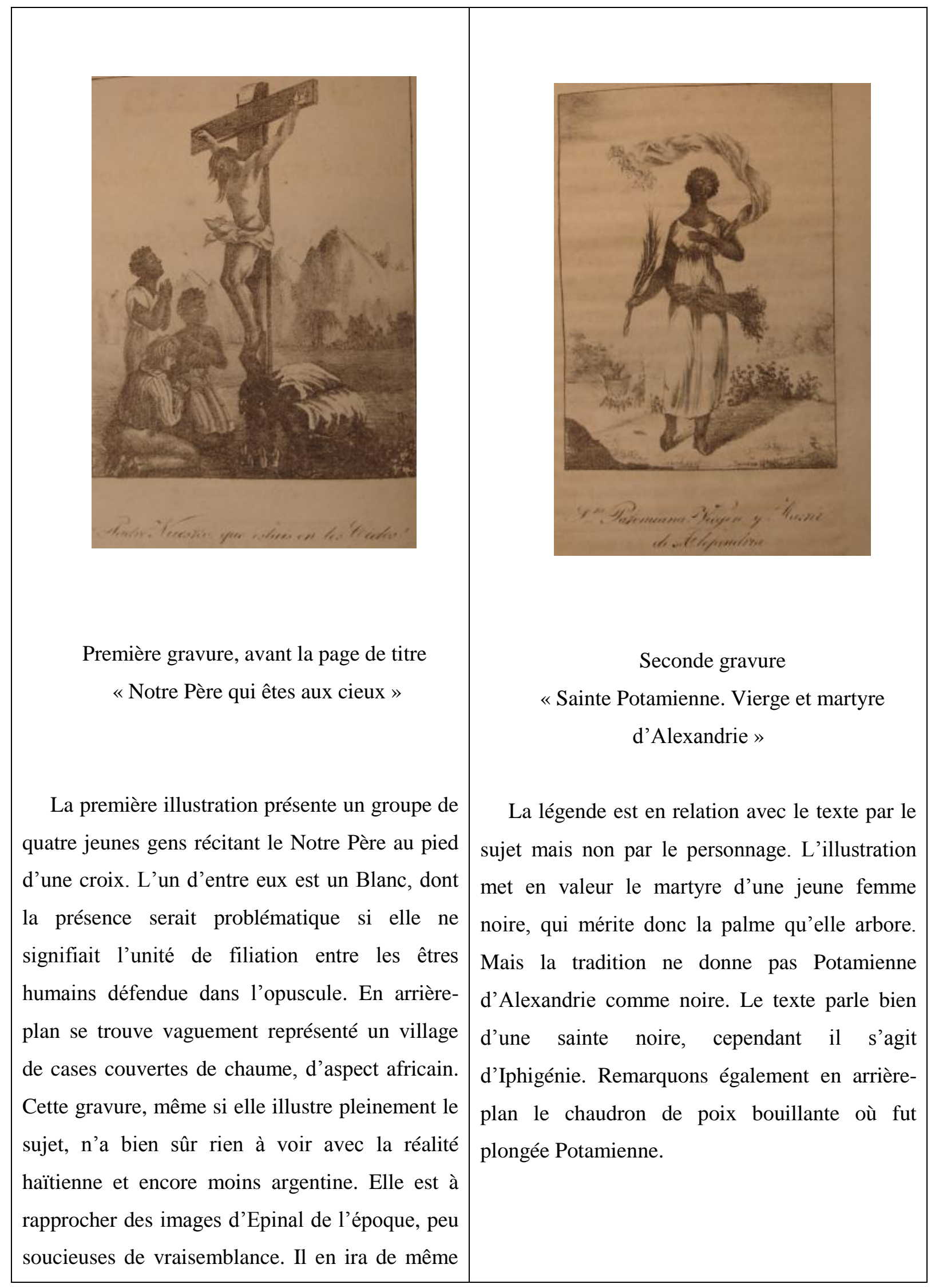




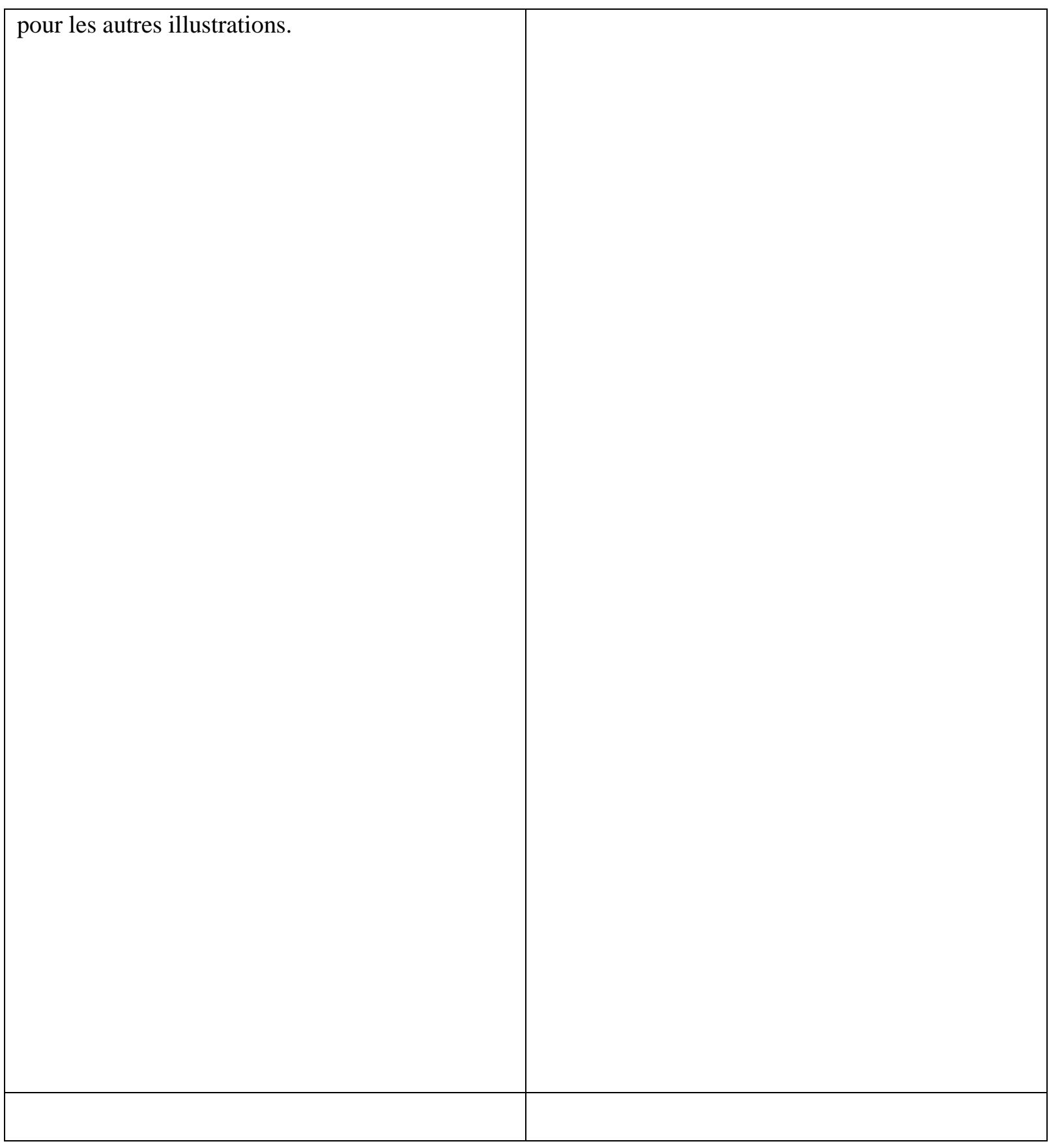




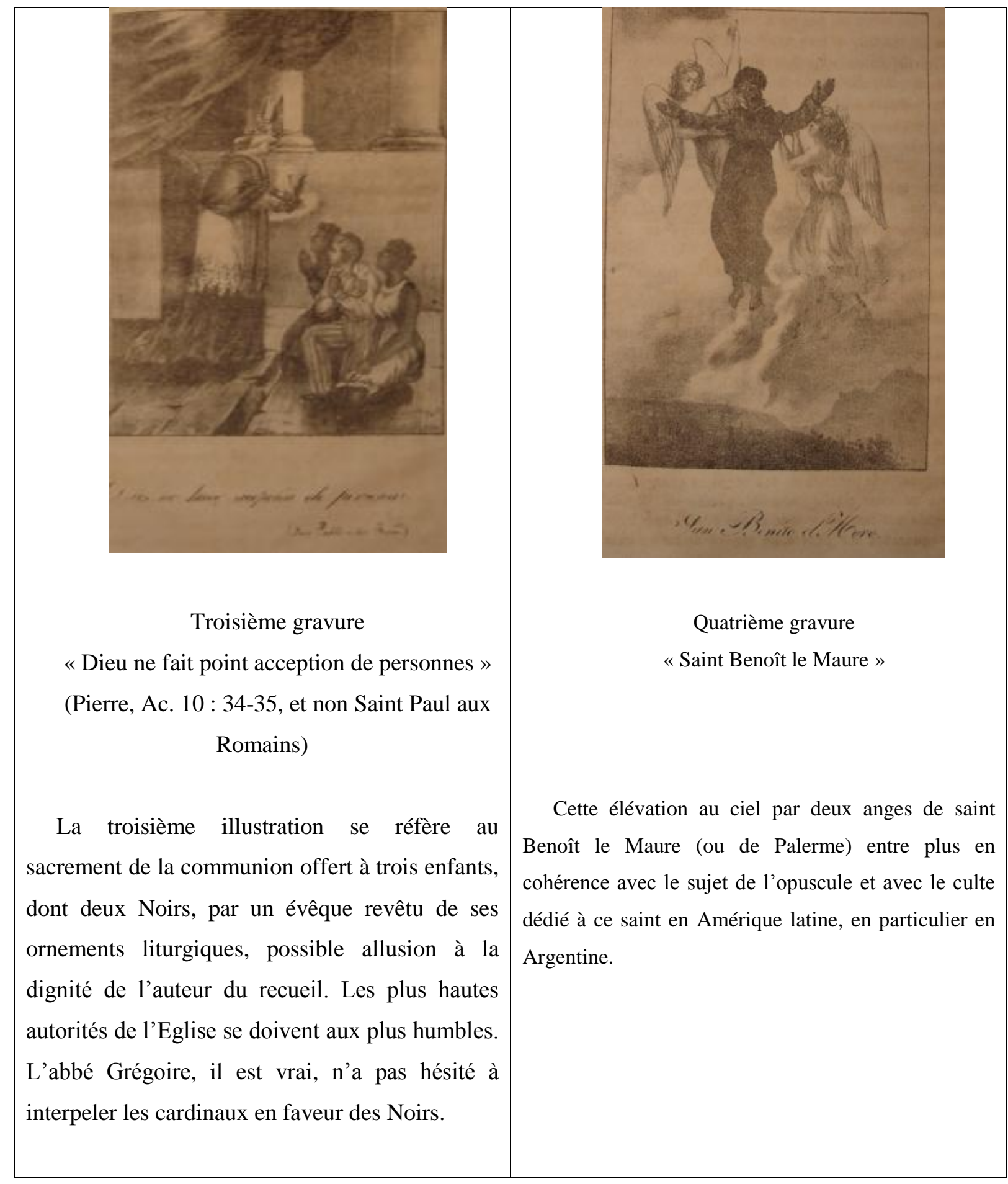


2-Gravures de l'édition française de 1822 qui n’ont pas été reproduites (volontairement censurées ?)

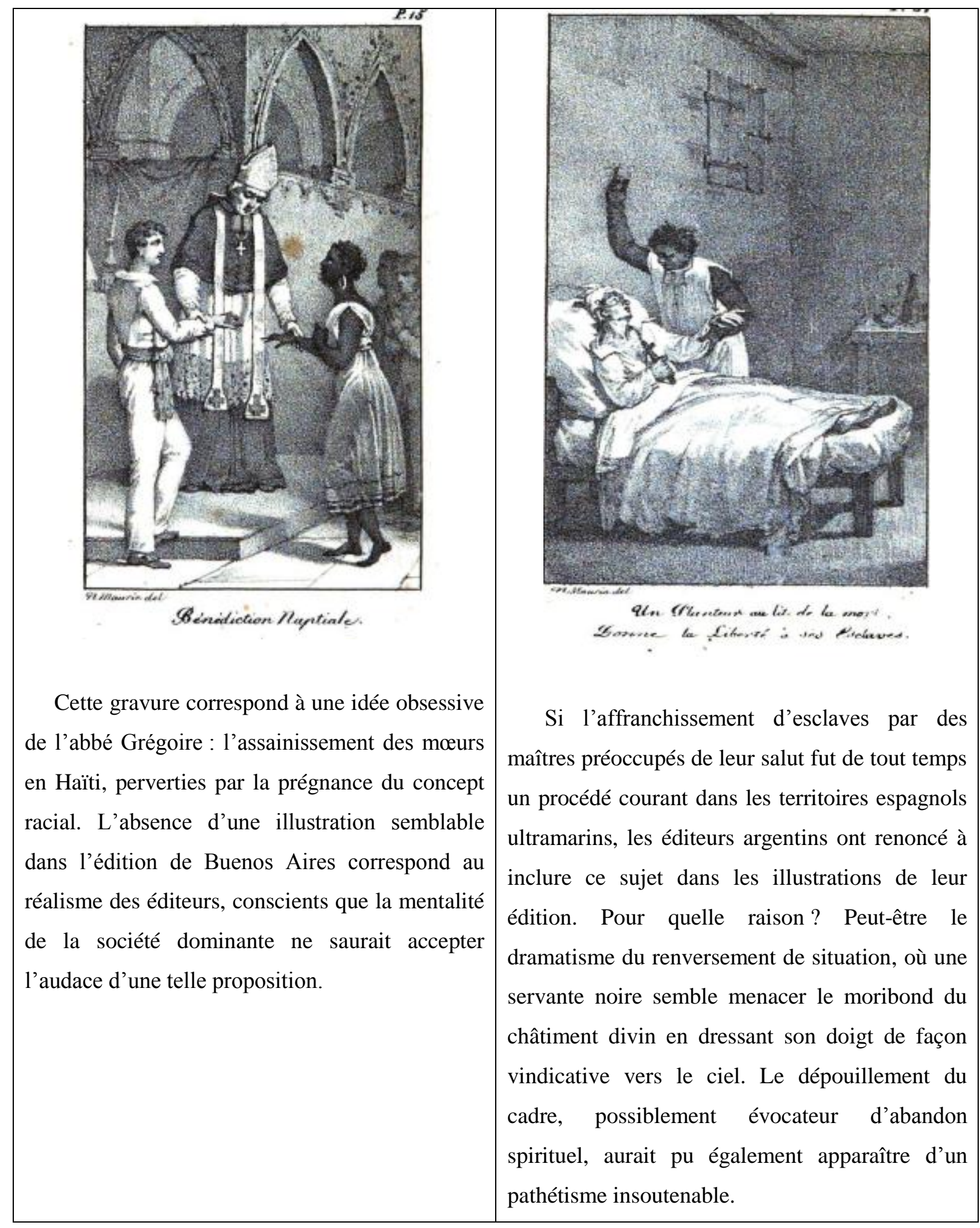




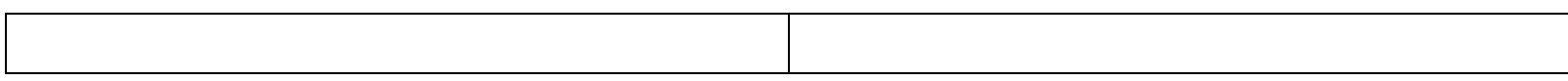

